\section{Quantitative retinal vascular calibre changes in diabetes and retinopathy: the Singapore Malay eye study}

FMA Islam¹, TT Nguyen', JJ Wang ${ }^{1,2}$, ES Tai ${ }^{3,4}$,

A Shankar, SM Saw ${ }^{5,6}$, T Aung, ${ }^{6,7}$, SC Lim,

P Mitchell ${ }^{2}$ and TY Wong ${ }^{1,6,7}$

\begin{abstract}
Purpose To describe the relationship of retinal vascular calibre with diabetes and diabetic retinopathy in an Asian population.

Methods A total of 3280 (78.7\% response) subjects, aged 40-80 years, of Malay ethnicity residing in Singapore participated in this population-based, cross-sectional study. Retinal vascular calibre was measured and summarized using a validated computer programme from digital retinal photographs. Diabetic retinopathy signs were graded from photographs using the modified Airlie House classification.
\end{abstract}

Results Of the 3004 subjects with data for this analysis, $682(22.7 \%)$ had diabetes, of whom 194 (28.4\%) had retinopathy. After multivariable adjustment, retinal arteriolar calibre was significantly wider in persons with diabetes (141 vs $139 \mu \mathrm{m}, P<0.001$ ); venular calibre was not associated with diabetes $(P=0.93)$. Among participants with diabetes, venular calibre increased from $218.7 \mu \mathrm{m}$ in those without retinopathy to $231.1 \mu \mathrm{m}$ in those with moderate and $231.4 \mu \mathrm{m}$ in those with severe retinopathy ( $P$ for trend $=<0.001$ ); arteriolar calibre was not associated with diabetic retinopathy.

Conclusions This study shows wider retinal arterioles in diabetes and wider venules in those with diabetic retinopathy in an Asian population. These findings confirm earlier data on white population, supporting the concept that a quantitative assessment of retinal vasculature may provide further insights into early diabetic microvascular damage.

Eye (2009) 23, 1719-1724; doi:10.1038/eye.2008.362; published online 12 December 2008
Keywords: retinal arteriolar calibre; retinal venular calibre; microcirculation; diabetes mellitus; diabetic retinopathy

There is an increasing evidence that alterations in the microvasculature play an important role in the pathogenesis early in the course of diabetes and its complications. ${ }^{1-5}$ Several studies have shown that subtle variations in retinal vascular calibre are related to prediabetes, diabetes development, and diabetic retinopathy. ${ }^{5-11}$ The Blue Mountain Eye Study $(\mathrm{BMES})^{10}$ and the Australian Diabetes, Obesity, and Lifestyle (AusDiab) ${ }^{8}$ reported that wider retinal arterioles are associated with diabetes, whereas wider retinal venules are associated with diabetic retinopathy. However, most earlier studies examined only white populations. Recent data from the Multi-Ethnic Study of Atherosclerosis (MESA) suggest that the association of retinal microvascular calibre with diabetes $^{7}$ may vary by race/ethnicity. For example, in a subgroup analysis, the association between wider arteriolar calibre and diabetes was evident in whites only, but not among other racial/ethnic groups; the association between wider venular calibre and diabetes was evident in Hispanics and Chinese. There are few studies in Asian populations. To address this, we studied the relationships of retinal vascular calibre with diabetes and diabetic retinopathy in a large Asian Malay population living in Singapore.

\section{Materials and methods}

\section{Study population}

The Singapore Malay Eye Study (SiMES) is a population-based, cross-sectional study of 3280
${ }^{1}$ Centre for Eye Research Australia, University of Melbourne, Australia

${ }^{2}$ Centre for Vision Research, University of Sydney, Australia

${ }^{3}$ Department of Endocrinology, Singapore General Hospital, Singapore, Singapore

${ }^{4}$ Centre for Molecular Epidemiology, National University of Singapore, Singapore, Singapore

${ }^{5}$ Department of Community, Occupational and Family Medicine, Yong Loo Lin School of Medicine, National University of Singapore, Singapore, Singapore

${ }^{6}$ Singapore Eye Research Institute, Singapore National Eye Centre, Singapore, Singapore

${ }^{7}$ Department of Ophthalmology, Yong Loo Lin School of Medicine, National University of Singapore, Singapore, Singapore

${ }^{8}$ Department of Medicine, Alexandra Hospital, Singapore, Singapore

Correspondence: TY Wong, Centre for Eye Research Australia, University of Melbourne, 32 Gisborne Street, Victoria 3002,

Australia

Tel: + 6139929 8352;

Fax: +6139662 3859

E-mail: twong@

unimelb.edu.au

Received: 16 April 2008

Accepted in revised form: 28 September 2008 Published online: 12 December 2008 
(78.7\% response) Malay adults aged $40-79$ years, living in Singapore, conducted between August 2004 and June 2006. The study design and detailed methodology are described elsewhere. ${ }^{12,13}$ Tenets of the Declaration of Helsinki were followed and approval was granted from the institutional review board of (IRB) the Singapore Eye Research Institute (SERI). Written informed consent was obtained from all participants.

Digital fundus photography was performed for 3264 participants. Of these, 3019 had photographs gradable for retinal vascular calibre. Another 15 were excluded because their right eye photographs were not gradable for diabetic retinopathy, or had signs of retinal vein occlusion. This left 3004 for this current study.

\section{Measurement of retinal vascular calibre}

Both eyes of each participant were photographed using a 45-degree 6.3 mega pixel digital non-mydriatic camera (Canon CR-DGi, Japan). Two photographic fields (optic disc and macula) were taken of each eye. Images were sent to the Retinal Vascular Imaging Centre, University of Melbourne, for grading. Retinal vascular calibre was measured using a computer-based programme by trained graders who were masked to participant characteristics. ${ }^{14}$ Photographs of the right eye were selected for measurement; the left eye was chosen only if measurements could not be performed on the right eye. For each image, all arterioles and venules coursing through an area of one-half to one-disc diameter away from the optic disc margin were measured and summarized as the central retinal artery equivalent (CRAE) and central retinal vein equivalent (CRVE), respectively. These equivalents represent the average calibre of arterioles and venules of that eye. Two hundred randomly selected retinal photographs were regraded by the same assessor to assess reproducibility, with intraclass correlation coefficients of 0.99 for CRAE and 0.94 for CRVE.

\section{Assessment of diabetic retinopathy}

For each eye, a retinopathy severity score was assigned using the modified Airlie House classification. ${ }^{15,16}$ For our analysis, levels $15-20$ were defined as minimal retinopathy, level 35 as mild, level 43 as moderate, and levels $47-90$ as severe diabetic retinopathy. Each person's retinopathy level was based on the scores for the right eye, as the majority of retinal vascular calibre measurements were obtained using this eye. $^{16}$

\section{Assessment of diabetes and other risk factors}

All participants had a comprehensive interview, a systemic examination, and laboratory investigations. Diabetes mellitus was defined as random glucose $\geqslant 11.1 \mathrm{mmol} / \mathrm{l}$, or use of diabetic medication or self-report of physician diagnosis. The criteria set by the Singapore census were used to define 'Malay' ethnicity. ${ }^{17}$ Height and weight were measured to determine body mass index (BMI). Blood pressure was measured on two occasions (5 min apart). If the blood pressures differed by more than $10 \mathrm{mmHg}$ systolic and $5 \mathrm{mmHg}$ diastolic, a third measurement was made. The blood pressure of the individual was then taken as the mean between the two closest readings. Hypertension was defined as systolic blood pressure of $\geqslant 140 \mathrm{mmHg}$, diastolic blood pressure of $\geqslant 90 \mathrm{mmHg}$, or current use of antihypertensive medications. Cigarette smoking was defined as current, past and never. Nonfasting blood samples were drawn and sent for the analysis of serum lipids (total cholesterol, high-density lipoprotein (HDL), and low-density lipoprotein (LDL) cholesterol), haemoglobin $\mathrm{A} 1_{\mathrm{C}}\left(\mathrm{HbA} 1_{\mathrm{C}}\right)$, and plasma glucose.

\section{Statistical analysis}

We used ANCOVA to estimate adjusted mean CRAE/ CRVE for participants with and without diabetes, and for categories of retinopathy in persons with diabetes. For the outcome variable of diabetes, the following models were constructed: model 1: adjustment for age and gender; model 2: adjustment for variables in model 1 plus systolic blood pressure, BMI, total cholesterol and current smoking; and model 3: adjustment for variables in model 2 plus CRVE in models for CRAE (and vice versa), which accounts for potential confounding from fellow vascular calibre. ${ }^{18}$

For the outcome variable of diabetic retinopathy, we further constructed the following models: model 4: adjustment for age, gender, glucose, systolic blood pressure, BMI, total cholesterol, and current smoking; and model 5: further adjustment for CRVE in models of CRAE, and vice versa. Tests of trend across severity of retinopathy categories were determined using the linear contrast with no retinopathy as the reference group. All analyses were performed in SPSS version 12.0.1 (SPSS Inc, Chicago, lL, USA).

\section{Results}

Baseline characteristics of the SiMES population are shown in Table 1. The excluded participants were older and had greater proportions with hypertension and 
Table 1 Characteristics of study population, the Singapore Malay Eye Study

\begin{tabular}{|c|c|c|c|c|c|c|c|c|c|}
\hline & \multirow{2}{*}{$\begin{array}{c}\begin{array}{c}\text { Excluded } \\
\text { participants }\end{array} \\
\mathrm{N}=276\end{array}$} & \multirow{2}{*}{ 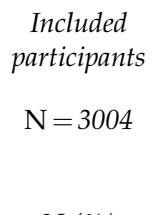 } & \multirow[b]{2}{*}{${ }^{*} \mathrm{P}$-value } & \multicolumn{3}{|c|}{$\begin{array}{l}\text { Participants without diabetes } \\
\qquad \mathrm{N}=2322\end{array}$} & \multicolumn{3}{|c|}{$\begin{array}{l}\text { Participants with diabetes } \\
\qquad \mathrm{N}=682\end{array}$} \\
\hline & & & & $\begin{array}{c}\text { No } \\
\text { retinopathy } \\
N=2249 \\
N(\%)\end{array}$ & $\begin{array}{c}\text { Any } \\
\text { retinopathy } \\
\mathrm{N}=73 \\
N(\%)\end{array}$ & *P-value & $\begin{array}{c}\text { No } \\
\text { retinopathy } \\
\mathrm{N}=488 \\
N(\%)\end{array}$ & $\begin{array}{c}\text { Any } \\
\text { retinopathy } \\
\mathrm{N}=194 \\
\mathrm{~N}(\%)\end{array}$ & ${ }^{*} \mathrm{P}$-value \\
\hline Gender, male & $128(46.4)$ & $1448(48.2)$ & 0.56 & $1101(49.0)$ & $46(63.0)$ & 0.02 & $233(47.7)$ & $68(35.1)$ & 0.003 \\
\hline Hypertension & $234(84.8)$ & $2012(67.0)$ & $<0.001$ & $1385(61.6)$ & $51(69.9)$ & 0.15 & $405(83.0)$ & $171(88.1)$ & 0.09 \\
\hline Diabetes & $82(29.9)$ & $682(22.7)$ & 0.007 & - & - & & $682(100)$ & - & \\
\hline \multirow[t]{2}{*}{ Cigarette smoker, current } & $107(39.2)$ & $1150(38.4)$ & 0.79 & $883(39.4)$ & $37(50.7)$ & 0.05 & $170(34.9)$ & $60(31.1)$ & 0.71 \\
\hline & Mean (SD) & Mean (SD) & & Mean (SD) & Mean (SD) & & Mean (SD) & Mean (SD) & \\
\hline Age, years & $70.2(8.3)$ & $57.6(10.6)$ & $<0.001$ & $56.4(10.7)$ & $55.9(10.9)$ & 0.68 & $61.9(9.6)$ & $61.5(8.2)$ & 0.61 \\
\hline Systolic BP, mmHg & $160.7(26.2)$ & $145.9(23.1)$ & $<0.001$ & $143.5(22.7)$ & $152.1(27.4)$ & 0.002 & $150.9(21.8)$ & $158.3(23.9)$ & $<0.001$ \\
\hline Diastolic BP, mmHg & $81.1(12.4)$ & $79.6(11.1)$ & 0.04 & 79.7 (11.1) & $82.5(13.2)$ & 0.03 & $79.1(10.5)$ & $78.7(11.5)$ & 0.65 \\
\hline Body mass index, $\mathrm{kg} / \mathrm{m}^{2}$ & $25.4(4.9)$ & $26.4(5.1)$ & 0.001 & $26.1(5.1)$ & $26.6(5.8)$ & 0.45 & $27.6(5.0)$ & $27.2(4.6)$ & 0.30 \\
\hline Serum glucose, mmol/1 & $7.3(3.9)$ & $6.8(3.7)$ & 0.03 & $5.47(1.28)$ & $5.78(1.56)$ & 0.05 & $10.7(5.2)$ & $12.1(5.7)$ & 0.002 \\
\hline Haemoglobin $\mathrm{A}_{1 \mathrm{C}}, \%$ & $6.6(1.6)$ & $6.4(1.5)$ & 0.06 & $5.85(0.59)$ & $5.99(0.64)$ & 0.04 & $8.23(2.05)$ & $8.98(1.93)$ & $<0.001$ \\
\hline Total cholesterol, $\mathrm{mmol} / \mathrm{l}$ & $5.8(1.3)$ & $5.6(1.2)$ & 0.003 & $5.66(1.11)$ & $5.75(1.23)$ & 0.49 & $5.47(1.19)$ & $5.36(1.40)$ & 0.28 \\
\hline HDL cholesterol, $\mathrm{mmol} / \mathrm{l}$ & $1.4(0.3)$ & $1.4(0.3)$ & 0.53 & $1.38(0.34)$ & $1.31(0.35)$ & 0.10 & $1.28(0.30)$ & $1.30(0.32)$ & 0.48 \\
\hline
\end{tabular}

$\mathrm{BP}=$ blood pressure; $\mathrm{HDL}=$ high-density lipoprotein.

${ }^{*} P$-value based on $\chi^{2}$ - (categorical) or independent sample $t$-tests, comparing the characteristics of included and excluded participants, with and without retinopathy and diabetes.

diabetes, higher levels of total cholesterol and serum glucose but lower BMI. Participants with retinopathy had higher levels of systolic blood pressure, serum glucose, and $\mathrm{HbA}_{1 \mathrm{C}}$.

In the study population, the mean $( \pm S D)$ CRAE was $135.5( \pm 15.7) \mu \mathrm{m}$ and the mean $( \pm$ SD) CRVE was 219.3 $( \pm 22.2) \mu \mathrm{m}$. There were $682(22.7 \%)$ with diabetes of whom 194 (28.4\%) had diabetic retinopathy. After controlling for age and gender, CRAE was significantly wider in persons with than without diabetes $(P=0.002)$, Table 2. This trend remained significant after further adjustment for variables in models 2 and 3. After adjusting for age, gender, systolic blood pressure, current smoking, BMI, and total cholesterol, CRVE was also significantly wider in persons with diabetes (model 2, Table 2, $P=0.02$ ). However, this association was no longer significant after further adjustment for CRAE (model 3, Table 2).

Figure 1 shows the distribution of CRAE and CRVE by levels of plasma glucose adjusting for variables in model 3. Increasing levels of glucose were associated with wider CRAE ( $P$ for trend $=0.006)$ but not CRVE ( $P$ for trend $=0.14)$.

Of the 2322 participants without diabetes, only 73 (3.1\%) had isolated retinopathy lesions (Table 3). There was no association between CRAE or CRVE, and the presence of isolated retinopathy lesions in participants without diabetes. Of 682 subjects with diabetes, there were $194(28.4 \%)$ with retinopathy, of which $55(8.1 \%)$
Table 2 Relationship of retinal arteriolar and venular calibres with diabetes status

\begin{tabular}{lccr}
\hline & \multicolumn{2}{c}{ Retinal vascular calibre, mean $(S E), \mu m$} \\
\cline { 2 - 4 } & No diabetes & Diabetes & *P-value \\
$\mathrm{N}=2322$ & $\mathrm{~N}=682$ & \\
\hline \multicolumn{5}{l}{ Retinal arteriolar calibre $(C R A E)$} \\
Model 1 & $139.0(0.32)$ & $141.1(0.61)$ & 0.002 \\
Model 2 & $139.2(0.33)$ & $142.2(0.61)$ & $<0.001$ \\
Model 3 & $139.1(0.28)$ & $141.3(0.52)$ & $<0.001$ \\
Retinal venular calibre (CRVE) & & \\
Model 1 & $218.7(0.46)$ & $221.3(0.86)$ & 0.008 \\
Model 2 & $219.3(0.48)$ & $221.6(0.88)$ & 0.02 \\
Model 3 & $219.6(0.41)$ & $219.7(0.76)$ & 0.93 \\
\hline
\end{tabular}

Data presented are ANCOVA models showing mean (SE) of retinal arteriolar and venular calibres (in $\mu \mathrm{m}$ ).

Model 1 was adjusted for age and gender.

Model 2 was adjusted for variables in model 1 plus systolic blood pressure, body mass index, total cholesterol, and current smoking.

Model 3 was adjusted for variables in model 2 and venular (in models of arteriolar calibre) and arteriolar calibres (in models of venular calibre).

${ }^{*} P<0.05$ comparing persons with and without diabetes.

with minimal, 37 (5.4\%) with mild, 37 (5.4\%) with moderat, and 65 (9.5\%) with severe retinopathy. Wider CRVE was associated with increasing severity of retinopathy ( $P$ for trend $=<0.001$ for all models). CRAE was not independently associated with diabetic retinopathy. 

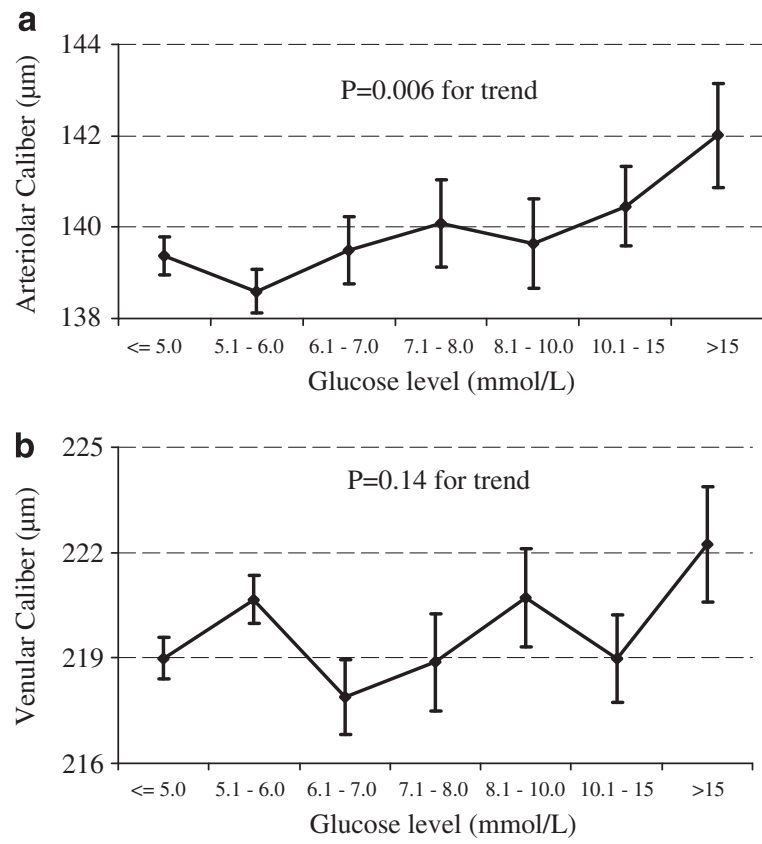

Figure 1 Distribution of (a) retinal arteriolar calibre $(\mu \mathrm{m})$ and (b) venular calibre $(\mu \mathrm{m})$ by glucose level. Data are mean (SE), adjusted for variables in model 3 (age, gender, systolic blood pressure, body mass index, total cholesterol, current smoking, and arteriolar calibre for venular calibre and venular calibre for arteriolar calibre).

\section{Discussion}

In this large population-based study in an Asian Malay population, we described the relationships of retinal arteriolar and venular calibre with diabetes and diabetic retinopathy. We show that persons with diabetes had significantly wider retinal arterioles than persons without. Wider arterioles, but not venules, were additionally associated with increasing levels of nonfasting plasma glucose in persons with and without diabetes. Among persons with diabetes, wider retinal venules were associated with increasing severity of diabetic retinopathy. These associations were independent of glucose levels and coexisting cardiovascular risk factors.

The overall percentage of retinopathy in our population $(28.4 \%)$ is similar to that in whites of the MESA (24.8\%). In the MESA, the prevalence rates of minimal, mild, moderate, and severe retinopathy among whites were $14.4,3.9,3.9$, and $2.6 \%$, respectively, ${ }^{19}$ whereas in SiMES, the corresponding prevalence rates were, $8.1,5.4,5.4$, and $9.5 \%$, respectively.

This pattern of association is consistent with those observed in the few studies available among white populations in the $\mathrm{BMES}^{10}$ and AusDiab study. ${ }^{8}$ Data from MESA study suggest that there may be racial variation of the effect of diabetes on the retinal vascular calibre. However, due to the small number of Asian participants, such an observation would need confirmation by other studies. ${ }^{7}$ We have now confirm that the effect of diabetes and diabetic retinopathy on the retinal vascular calibre in our Asian population are similar to that previously shown in white/Caucasian populations from MESA, ${ }^{7}$ BMES, $^{10}$ and AusDiab ${ }^{8}$ studies. Similarly, we have also previously shown that the effects of blood pressure on the retinal vascular calibre in this population are similar to that observed in white populations. ${ }^{20}$ Our study now clearly shows that in Asian Malays, as in white population, wider retinal arterioles are associated with diabetes. The association of wider retinal venules with diabetic retinopathy signs in our study is also consistent with clinical experience, as well as with findings from white population from BMES, ${ }^{10}$ AusDiab, ${ }^{8}$ MESA, ${ }^{7}$ and Wisconsin Epidemiological Study of Diabetic Retinopathy (WESDR). ${ }^{6,9}$

The mechanisms underlying wider retinal arterioles with diabetes are uncertain, but multiple aetiologies have been suggested, including impaired autoreguation of small vessels caused by hyperglycaemia and hypoxia. ${ }^{21,22}$ Other pathophysiological mechanisms underlying the association between wider retinal venules and diabetic retinopathy have previously shown in experimental studies, such as inflammation associated with wider retinal venules in both humans ${ }^{23}$ and animals, ${ }^{24}$ partly reflecting increased nitrous oxide levels. ${ }^{25}$ Ocular inflammation is one of pathogenic factors in the development and progression of diabetic retinopathy. ${ }^{26-28}$ In contrast to the current findings, we found no association between retinal arteriolar or venular calibre and retinopathy lesions in participants without diabetes, supporting a concept that retinopathy signs in persons without diabetes may be due to mechanisms different from that for diabetic retinopathy, such as hypertension. ${ }^{11,29}$

The strengths of this study include its large population-based sample, use of standardized methods to measure retinal vascular calibre, and grade retinopathy. There are important limitations to this study, which should be noted. First, the cross-sectional nature of the study limits our ability to assess the temporal sequence of the associations observed. Second, we obtained 45-degree non-stereoscopic photographs of two fields (macula and optic disc) to grade diabetic retinopathy, which is less sensitive in detecting retinopathy from the seven stereoscopic photographic fields. This could have led to an underestimation of the proportion with retinopathy. Third, the measurement of serum glucose and lipids were not from fasting venous samples. Furthermore, there could be misclassification of 
Table 3 Relationship of retinal arteriolar and venular calibres with and without retinopathy in participants without diabetes and by the severity of retinopathy in participants with diabetes

\begin{tabular}{|c|c|c|c|c|c|c|c|c|c|}
\hline & \multicolumn{9}{|c|}{ Retinal vascular calibre, mean (SE), $\mu m$} \\
\hline & \multicolumn{3}{|c|}{ No diabetes, $\mathrm{N}=2322$} & \multicolumn{6}{|c|}{ Diabetes, $\mathrm{N}=682$} \\
\hline & $\begin{array}{c}\text { No } \\
\text { retinopathy } \\
\mathrm{N}=2249 \\
(96.7 \%)\end{array}$ & $\begin{array}{c}\text { Any } \\
\text { retinopathy } \\
\mathrm{N}=73 \\
(3.1 \%)\end{array}$ & P-value & $\begin{array}{c}\text { No } \\
\text { retinopathy } \\
\mathrm{N}=488 \\
(71.6 \%)\end{array}$ & $\begin{array}{c}\text { Minimum } \\
\text { retinopathy } \\
\mathrm{N}=55 \\
(8.1 \%)\end{array}$ & $\begin{array}{l}\text { Mild } \\
\text { retinopathy } \\
\mathrm{N}=37 \\
(5.4 \%)\end{array}$ & $\begin{array}{c}\text { Moderate } \\
\text { retinopathy } \\
\mathrm{N}=37(5.4 \%)\end{array}$ & $\begin{array}{l}\text { Severe } \\
\text { retinopathy } \\
\mathrm{N}=65 \\
(9.5 \%)\end{array}$ & $\begin{array}{l}\mathrm{P} \text { for } \\
\text { trend }\end{array}$ \\
\hline \multicolumn{10}{|c|}{ Retinal arteriolar calibre (CRAE) } \\
\hline Model 1 & $139.1(0.33)$ & $140.3(1.82)$ & 0.51 & $140.3(0.71)$ & $141.7(2.10)$ & $146.0(2.56)$ & $143.0(2.58)$ & 137.9 (1.94) & 0.50 \\
\hline Model 4 & $139.3(0.34)$ & $141.6(1.82)$ & 0.21 & $140.4(0.74)$ & $141.5(2.10)$ & $146.7(2.57)$ & $145.3(2.74)$ & $140.4(2.08)$ & 0.52 \\
\hline Model 5 & $139.1(0.29)$ & $140.9(1.56)$ & 0.25 & $140.9(0.65)$ & $141.4(1.85)$ & $146.3(2.26)$ & $140.6(2.43)$ & $136.7(1.85)$ & 0.07 \\
\hline \multicolumn{10}{|c|}{ Retinal venular calibre (CRVE) } \\
\hline Model 1 & $218.9(0.46)$ & $221.5(2.54)$ & 0.31 & $217.8(1.01)$ & $219.5(3.02)$ & $220.4(3.69)$ & $230.1(3.70)^{*}$ & $230.8(2.79)^{*}$ & $<0.001$ \\
\hline Model 4 & $219.5(0.49)$ & $220.9(2.60)$ & 0.60 & $218.4(1.10)$ & $220.2(3.08)$ & $221.0(3.79)$ & $234.3(4.02)^{*}$ & $231.1(3.05)^{*}$ & $<0.001$ \\
\hline Model 5 & $219.3(0.41)$ & $219.0(2.23)$ & 0.89 & $218.7(0.96)$ & $219.8(2.71)$ & $216.9(3.32)$ & $231.1(3.53)^{*}$ & $231.4(2.68)^{*}$ & $<0.001$ \\
\hline
\end{tabular}

Data presented are ANCOVA models showing mean (standard error) of retinal arteriolar and venular calibres (in $\mu \mathrm{m}$ ).

Model 4 was adjusted for age, gender, systolic blood pressure, body mass index, total cholesterol, blood glucose, and current smoking.

Model 5 was adjusted for variables in model 4 and also for venular (in models of arteriolar calibre) and arteriolar calibres (in models of venular calibre).

${ }^{*} P<0.05$, comparing adjusted mean with no retinopathy as the reference group.

diabetes and hypertension status from one random blood test and blood pressure reading. Finally, there are other factors that could influence retinal vascular calibre, such as genetic parameters, that were not able to control. By adjusting for the alternate vessel, we have negated some effects from these other 'non-measurable' factors. ${ }^{18}$

In conclusion, we have shown subtle variations in the retinal microvascular in diabetes and diabetic retinopathy in an Asian population. Wider retinal arterioles were associated with diabetes and increasing levels of hyperglycaemia, whereas wider venules were associated with increasing severity of diabetic retinopathy. These findings add further to the concept that an assessment of retinal vascular calibre may provide insights into early microvascular processes associated with diabetes and its complications.

\section{Acknowledgements}

We thank the staff and participants in the SiMES study for their important contributions. This study was supported by the National Medical Research Council Grants No 0796/2003, 0863/2004 and CSI/0002/2005 and Biomedical Research Council Grant No 501/1/25-5. Additional support was provided by the Singapore Tissue Network and the Ministry of Health, Singapore.

\section{Conflict/proprietary interest}

None.

\section{References}

1 Nguyen TT, Wang JJ, Islam FM, Mitchell P, Tapp RJ, Zimmet $\mathrm{PZ}$ et al. Retinal arteriolar narrowing predicts incidence of diabetes: the Australian Diabetes, Obesity and Lifestyle (AusDiab) Study. Diabetes 2008; 57(3): 536-539.

2 Rogers SL, Tikellis G, Cheung N, Tapp R, Shaw J, Zimmet $\mathrm{PZ}$ et al. Retinal arteriolar caliber predicts incident retinopathy: the Australian Diabetes, Obesity and Lifestyle (AusDiab) study. Diabetes Care 2008; 31(4): 761-763.

3 Wong TY, Shankar A, Klein R, Klein BEK, Hubbard LD. Retinal arteriolar narrowing, hypertension, and subsequent risk of diabetes mellitus. Arch Intern Med 2005; 165(9): 1060-1065.

4 Wong TY, Klein R, Sharrett AR, Schmidt MI, Pankow JS, Couper DJ et al., ARIC Investigators. Retinal arteriolar narrowing and risk of diabetes mellitus in middle-aged persons. JAMA 2002; 287(19): 2528-2533.

5 Alibrahim E, Donaghue KC, Rogers S et al. Retinal vascular caliber and risk of retinopathy in young patients with type 1 diabetes. Ophthalmology 2006; 113(9): 1499-1503.

6 Klein R, Klein BEK, Moss SE, Wong TY, Sharrett AR. Retinal vascular caliber in persons with type 2 diabetes: the Wisconsin Epidemiological Study of Diabetic Retinopathy: XX. Ophthalmology 2006; 113(9): 1488-1498.

7 Nguyen TT, Wang JJ, Sharrett AR, Islam FM, Klein R, Klein BE et al. Relationship of retinal vascular caliber with diabetes and retinopathy: the Multi-Ethnic Study of Atherosclerosis (MESA). Diabetes Care 2008; 31(3): 544-549.

8 Tikellis G, Wang JJ, Tapp R, Simpson R, Mitchell P, Zimmet PZ et al. The relationship of retinal vascular calibre to diabetes and retinopathy: the Australian Diabetes, Obesity and Lifestyle (AusDiab) study. Diabetologia 2007; 50(11): 2263-2271.

9 Klein R, Klein BE, Moss SE, Wong TY, Hubbard L, Cruickshanks $\mathrm{KJ}$ et al. Retinal vascular abnormalities in 
persons with type 1 diabetes: the Wisconsin Epidemiologic Study of Diabetic Retinopathy: XVIII. Ophthalmology 2003; 110(11): 2118-2125.

10 Kifley A, Wang JJ, Cugati S, Wong TY, Mitchell P. Retinal vascular caliber, diabetes, and retinopathy. Am J Ophthalmol 2007; 143(6): 1024-1026.

11 Nguyen TT, Wang JJ, Wong TY. Retinal vascular changes in pre-diabetes and prehypertension: new findings and their research and clinical implications. Diabetes Care 2007; 30(10): 2708-2715.

12 Foong AW, Saw SM, Loo JL, Shen S, Loon SC, Rosman M et al. Rationale and methodology for a population-based study of eye diseases in Malay people: The Singapore Malay eye study (SiMES). Ophthalmic Epidemiol 2007; 14(1): 25-35.

13 Wong TY, Chong EW, Wong WL, Rosman M, Aung T, Loo JL et al., Singapore Malay Eye Study Team. Prevalence and causes of visual impairment and blindness in an urban Malay Population: the Singapore Malay Eye Study. Arch of Ophthalmol 2008; 126(8): 1091-1099.

14 Wong TY, Knudtson MD, Klein R, Klein BE, Meuer SM, Hubbard LD. Computer-assisted measurement of retinal vessel diameters in the Beaver Dam Eye Study: methodology, correlation between eyes, and effect of refractive errors. Ophthalmology 2004; 111(6): 1183-1190.

15 Diabetic retinopathy study. Report Number 6. Design, methods, and baseline results. Report Number 7. A modification of the Airlie House classification of diabetic retinopathy. Prepared by the Diabetic Retinopathy. Invest Ophthalmol Vis Sci 1981; 21(1 Pt 2): 1-226.

16 Wong TY, Cheung N, Tay WT, Wang JJ, Aung T, Saw SM et al. Prevalence and risk factors for diabetic retinopathy. The Singapore Malay Eye Study. Ophthalmology 2008; 48(1): 52-57.

17 Leow BG. Singapore Census of Population 2000: Statistical Release 1-Demographic Characteristics. Department of Statistics: Government of Singapore, Singapore, 2001.

18 Liew G, Sharrett AR, Kronmal R, Klein R, Wong TY, Mitchell $P$ et al. Measurement of retinal vascular caliber: issues and alternatives to using the arteriole to venule ratio. Invest Ophthalmol Vis Sci 2007; 48(1): 52-57.
19 Wong TY, Klein R, Islam FM, Cotch MF, Folsom AR, Klein $\mathrm{BE}$ et al. Diabetic retinopathy in a multi-ethnic cohort in the United States. Am J Ophthalmol 2006; 141(3): 446-455.

20 Sun C, Liew G, Wang JJ, Mitchell P, Saw SM, Aung T et al. Retinal vascular caliber, blood pressure, and cardiovascular risk factors in an Asian population: the Singapore Malay Eye Study. Invest Ophthalmol Vis Sci 2008; 49(5): 1784-1790.

21 Mandecka A, Dawczynski J, Blum M, Müller N, Kloos C, Wolf $\mathrm{G}$ et al. Influence of flickering light on the retinal vessels in diabetic patients. Diabetes Care 2007; 30(12): 3048-3052.

22 Grunwald JE, Brucker AJ, Schwartz SS, Braunstein SN, Baker L, Petrig BL et al. Diabetic glycemic control and retinal blood flow. Diabetes 1990; 39(5): 602-607.

23 Tamai K, Matsubara A, Tomida K, Matsuda Y, Morita H, Armstrong $\mathrm{D}$ et al. Lipid hydroperoxide stimulates leukocyte-endothelium interaction in the retinal microcirculation. Exp Eye Res 2002; 75(1): 69-75.

24 Kolodjaschna J, Berisha F, Lung S, Schaller G, Polska E, Jilma B et al. LPS-induced microvascular leukocytosis can be assessed by blue-field entoptic phenomenon. Am J Physiol Heart Circ Physiol 2004; 287(2): H691-H694.

25 Chester AH, Borland JA, Buttery LD, Mitchell JA Cunningham DA, Hafizi $S$ et al. Induction of nitric oxide synthase in human vascular smooth muscle: interactions between proinflammatory cytokines. Cardiovasc Res 1998; 38(3): 814-821.

26 Miyamoto K, Khosrof S, Bursell SE, Rohan R, Murata T, Clermont AC et al. Prevention of leukostasis and vascular leakage in streptozotocin-induced diabetic retinopathy via intercellular adhesion molecule-1 inhibition. Proc Natl Acad Sci USA 1999; 96(19): 10836-10841.

27 Izuora KE, Chase HP, Jackson WE, Coll JR, Osberg IM, Gottlieb PA et al. Inflammatory markers and diabetic retinopathy in type 1 diabetes. Diabetes Care 2005; 28(3): 714-715.

28 Joussen AM, Poulaki V, Le ML, Koizumi K, Esser C, Janicki $\mathrm{H}$ et al. A central role for inflammation in the pathogenesis of diabetic retinopathy. FASEB J 2004; 18(12): 1450-1452.

29 Wong TY, Mitchell P. Hypertensive retinopathy. N Engl J Med 2004; 351(22): 2310-2317. 